NASA/TM-2002-210733

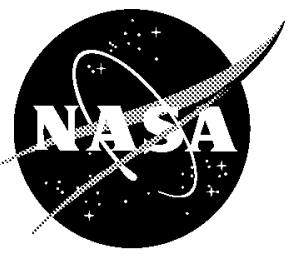

\title{
String Stability of a Linear Formation Flight Control System
}

Michael J. Allen, Jack Ryan, and Curtis E. Hanson

NASA Dryden Flight Research Center

Edwards, California

James F. Parle

University of Southern California

Los, Angeles, California

August 2002 


\section{The NASA STI Program Office...in Profile}

Since its founding, NASA has been dedicated to the advancement of aeronautics and space science. The NASA Scientific and Technical Information (STI) Program Office plays a key part in helping NASA maintain this important role.

The NASA STI Program Office is operated by Langley Research Center, the lead center for NASA's scientific and technical information. The NASA STI Program Office provides access to the NASA STI Database, the largest collection of aeronautical and space science STI in the world. The Program Office is also NASA's institutional mechanism for disseminating the results of its research and development activities. These results are published by NASA in the NASA STI Report Series, which includes the following report types:

- TECHNICAL PUBLICATION. Reports of completed research or a major significant phase of research that present the results of NASA programs and include extensive data or theoretical analysis. Includes compilations of significant scientific and technical data and information deemed to be of continuing reference value. NASA's counterpart of peer-reviewed formal professional papers but has less stringent limitations on manuscript length and extent of graphic presentations.

- TECHNICAL MEMORANDUM. Scientific and technical findings that are preliminary or of specialized interest, e.g., quick release reports, working papers, and bibliographies that contain minimal annotation. Does not contain extensive analysis.

- CONTRACTOR REPORT. Scientific and technical findings by NASA-sponsored contractors and grantees.
- CONFERENCE PUBLICATION. Collected papers from scientific and technical conferences, symposia, seminars, or other meetings sponsored or cosponsored by NASA.

- SPECIAL PUBLICATION. Scientific, technical, or historical information from NASA programs, projects, and mission, often concerned with subjects having substantial public interest.

- TECHNICAL TRANSLATION. Englishlanguage translations of foreign scientific and technical material pertinent to NASA's mission.

Specialized services that complement the STI Program Office's diverse offerings include creating custom thesauri, building customized databases, organizing and publishing research results...even providing videos.

For more information about the NASA STI Program Office, see the following:

- Access the NASA STI Program Home Page at http://www.sti.nasa.gov

- E-mail your question via the Internet to help@sti.nasa.gov

- Fax your question to the NASA Access Help Desk at (301) 621-0134

- Telephone the NASA Access Help Desk at (301) 621-0390

- Write to:

NASA Access Help Desk

NASA Center for AeroSpace Information 7121 Standard Drive Hanover, MD 21076-1320 
NASA/TM-2002-210733

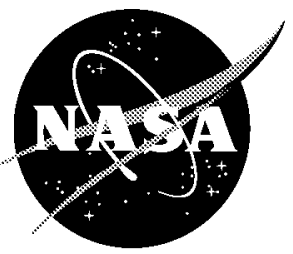

\section{String Stability of a Linear Formation Flight Control System}

Michael J. Allen, Jack Ryan, and Curtis E. Hanson

NASA Dryden Flight Research Center

Edwards, California

James F. Parle

University of Southern California

Los Angeles, California

National Aeronautics and

Space Administration

Dryden Flight Research Center

Edwards, California 93523-0273

August 2002 


\section{NOTICE}

Use of trade names or names of manufacturers in this document does not constitute an official endorsement of such products or manufacturers, either expressed or implied, by the National Aeronautics and Space Administration.

Available from the following:

NASA Center for AeroSpace Information (CASI)

7121 Standard Drive

Hanover, MD 21076-1320

(301) 621-0390
National Technical Information Service (NTIS) 5285 Port Royal Road Springfield, VA 22161-2171

(703) $487-4650$ 


\title{
STRING STABILITY OF A LINEAR FORMATION FLIGHT CONTROL SYSTEM
}

\author{
Michael J. Allen, ${ }^{*}$ Jack Ryan, ${ }^{\dagger}$ Curtis E. Hanson ${ }^{\ddagger}$ \\ NASA Dryden Flight Research Center \\ Edwards, California \\ James F. Parle $\$$ \\ University of Southern California \\ Los Angeles, California
}

\begin{abstract}
$\underline{\text { Abstract }}$
String stability analysis of an autonomous formation flight system was performed using linear and nonlinear simulations. String stability is a measure of how position errors propagate from one vehicle to another in a cascaded system. In the formation flight system considered here, each $i^{\text {th }}$ aircraft uses information from itself and the preceding $\left((i-1)^{t h}\right)$ aircraft to track a commanded relative position. A possible solution for meeting performance requirements with such a system is to allow string instability. This paper explores two results of string instability and outlines analysis techniques for string unstable systems. The three analysis techniques presented here are: linear, nonlinear formation performance, and ride quality. The linear technique was developed from a worst-case scenario and could be applied to the design of a string unstable controller. The nonlinear formation performance and ride quality analysis techniques both use nonlinear formation simulation. Three of the four formation-controller gain-sets analyzed in this paper were limited more by ride quality than by performance. Formations of up to seven aircraft in a cascaded formation could be used in the presence of light gusts with this string unstable system.

\footnotetext{
*Aerospace Engineer

$\uparrow$ Aerospace Engineer

tAerospace Engineer

§Aerospace Engineer

Copyright (C 2002 by the American Institute of Aeronautics and

Note that use of trade names or names of manufacturers in this
} Astronautics, Inc. No copyright is asserted in the United States under Title 17, U.S. Code. The U.S. Government has a royalty-free license to exercise all rights under the copyright claimed herein for Governmental purposes. All other rights are reserved by the copyright owner. document does not constitute an official endorsement of such products or manufacturers, either expressed or implied, by the National Aeronautics and Space Administration.
\end{abstract}

\section{$\underline{\text { Nomenclature }}$}

$\underline{\text { Acronyms }}$

6-DOF six degrees-of-freedom

AFF Autonomous Formation Flight

BIBO bounded input, bounded output

DFRC Dryden Flight Research Center (Edwards Air Force Base, California)

F/A-18 twin-engine jet fighter aircraft (Boeing, USA)

GPS Global Positioning System

ISO International Organization for Standardization

MSDV motion sickness dose value, $(\mathrm{m} / \mathrm{sec})^{1.5}$

NASA National Aeronautics and Space Administration (Washington, D. C.)

PID proportional-plus-integral-plus-derivative

PSD Power Spectral Density

SISO single input, single output

$\underline{\text { Symbols }}$

amp amplitude of oscillation (peak value)

$a_{w} \quad$ frequency-weighted acceleration, $\mathrm{m} / \mathrm{s}^{2}$

$\mathrm{dB} \quad$ decibels

E East direction in Earth tangent reference frame

$E_{i, a b s} \quad$ absolute-position error of the $i^{t h}$ aircraft, $\mathrm{ft}$

$E_{i, r e l} \quad$ relative-position error of the $i^{t h}$ aircraft, $\mathrm{ft}$

$G_{1}(s) \quad$ example of a string unstable closed-loop transfer function

$G_{2}(s) \quad$ example of a string stable closed-loop transfer function

1 


\begin{tabular}{|c|c|}
\hline$G(s)$ & closed-loop transfer function \\
\hline $\mathrm{Hz}$ & hertz, cycles/sec \\
\hline$i$ & aircraft formation index \\
\hline$j$ & imaginary number, $\sqrt{ }(-1)$ \\
\hline$K_{\phi}$ & bank angle gain \\
\hline$K_{I_{Y}}$ & lateral position integral gain \\
\hline$K_{I_{Z}}$ & vertical position integral gain \\
\hline$K_{m}$ & motion sickness constant \\
\hline$K_{N_{Z}}$ & normal acceleration gain \\
\hline$K_{V_{Y}}$ & lateral velocity gain \\
\hline$K_{V_{Z}}$ & vertical velocity gain \\
\hline$K_{Y}$ & lateral position gain \\
\hline$K_{Z}$ & vertical position gain \\
\hline $\max$ & maximum \\
\hline$M_{m}$ & $\begin{array}{l}\text { peak magnitude of the closed-loop transfer } \\
\text { function }\end{array}$ \\
\hline$n$ & total number of aircraft in series formation \\
\hline $\mathrm{N}$ & $\begin{array}{l}\text { North direction in earth tangent reference } \\
\text { frame }\end{array}$ \\
\hline$N_{Z}$ & vertical acceleration, $g$ \\
\hline$P_{i}$ & position of the $\mathrm{i}^{\text {th }}$ aircraft, $\mathrm{ft}$ \\
\hline$P_{i n}$ & single position input, $\mathrm{ft}$ \\
\hline$P_{o, i}$ & initial position of the aircraft, $\mathrm{ft}$ \\
\hline$P_{\text {out }}$ & single position output, $\mathrm{ft}$ \\
\hline$P_{Y_{\text {leading }}}$ & Y-axis leading aircraft position, $\mathrm{ft}$ \\
\hline$P_{Y_{\text {trailing }}}$ & Y-axis trailing aircraft position, $\mathrm{ft}$ \\
\hline$P_{Z_{\text {leading }}}$ & $\mathrm{Z}$-axis leading aircraft position, $\mathrm{ft}$ \\
\hline$P_{Z_{\text {trailing }}}$ & $\mathrm{Z}$-axis trailing aircraft position, $\mathrm{ft}$ \\
\hline$R_{n}$ & $\begin{array}{l}\text { ratio of absolute-position error, given by } \\
\text { equation (6) }\end{array}$ \\
\hline$s$ & Laplace transform variable, $s=\sigma+j \omega$ \\
\hline$t$ & time, seconds \\
\hline $\mathrm{X}$ & $\begin{array}{l}\text { longitudinal axes of formation reference } \\
\text { frame }\end{array}$ \\
\hline $\mathrm{Y}$ & lateral axes of formation reference frame \\
\hline Z & vertical axes of formation reference frame \\
\hline$\gamma_{1}$ & input direction, deg \\
\hline$\gamma_{2}$ & output direction, deg \\
\hline$\Delta P_{Y}$ & lateral relative position, $\mathrm{ft}$ \\
\hline
\end{tabular}

$\begin{array}{ll}\Delta P_{Y_{\text {cmd }}} & \text { lateral relative-position command, } \mathrm{ft} \\ \Delta P_{Y_{\text {err }}} & \text { lateral relative-position error, } \mathrm{ft} \\ \Delta P_{Z} & \text { vertical relative position, } \mathrm{ft} \\ \Delta P_{Z_{\text {cmd }}} & \text { vertical relative-position command, } \mathrm{ft} \\ \Delta P_{Z_{\text {err }}} & \text { vertical relative-position error, } \mathrm{ft} \\ \Delta V_{Y} & \text { lateral relative velocity, } \mathrm{ft} / \mathrm{sec} \\ \Delta V_{Y_{\text {err }}} & \text { lateral relative-velocity error, } \mathrm{ft} / \mathrm{sec} \\ \Delta V_{Z} & \text { vertical relative velocity, } \mathrm{ft} / \mathrm{sec} \\ \Delta V_{Z_{e r r}} & \text { vertical relative-velocity error, } \mathrm{ft} / \mathrm{sec} \\ \sigma & \text { real part of complex number } \mathrm{s}, \\ \phi & \quad s=\text { } \sigma+j \omega \\ \omega & \text { bank angle, deg } \\ \omega_{m} & \text { input frequency, rad/sec } \\ & \text { frequency of } \mathrm{M} \mathrm{m}, \mathrm{rad} / \mathrm{sec}\end{array}$

Loosely speaking, string stability is a measure of how errors propagate through a series of interconnected systems. A formation of aircraft is considered string stable if, for instance, a position error between the first and second aircraft results in a smaller position error between the second and third aircraft.

An example of string instability can be found by considering a formation of piloted aircraft in low-visibility conditions such as clouds. With this limited visibility, each pilot can only see the aircraft directly ahead and attempts to track a position relative to that aircraft. Typically, any position changes to the first aircraft are reacted to by the second aircraft with slight overshoot. Each aircraft overshoots the motion of the previous aircraft. This can cause unacceptable motion of the last aircraft in the string.

There has been much work done investigating string instability, most of which is directed toward automotive technology such as adaptive cruise control ${ }^{1}$ and the automated highway system. ${ }^{2,3}$ The vast majority of this work has been directed toward investigating varying strategies to avoid or correct string instability. The common conclusions are that either large amounts of intervehicle communication are needed, or trajectory following or headway guidance approaches are needed. $^{4,5}$

Most studies are constrained by the requirement that a formation of infinite size must be string stable. The system described in this paper is limited in formation 
size and is therefore free to explore string unstable systems.

\section{Autonomous Formation Flight}

This paper focuses its investigation on the string-stability properties of the Autonomous Formation Flight (AFF) control system. The AFF program was developed to try to obtain drag reduction, and hence improve fuel efficiency, through formation flight. ${ }^{6}$

In a manner similar to birds in a V-shaped formation, each individual aircraft can reduce its induced drag through wingtip-vortex interaction. ${ }^{6,7,8,9}$ A full description of the AFF program can be found in references 6 and 10. Two F/A-18 aircraft in close formation flight are shown in figure 1.

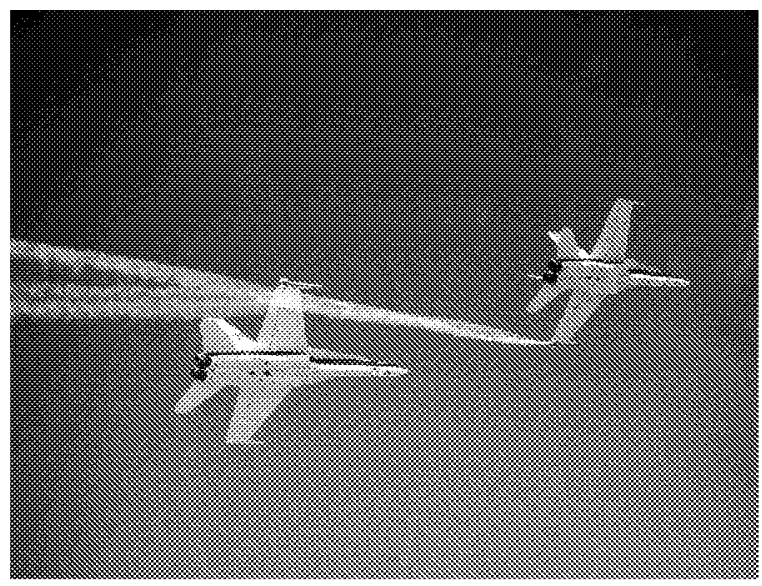

EC01-0328-03

Figure 1. Two F/A-18 aircraft in formation flight.

The AFF system shown in figure 2 was used to position a trailing aircraft relative to a leading aircraft.
The design objectives were to have the trailing aircraft, in a two-ship formation, maintain relative position in the lateral and vertical directions. Response to commands was to be brisk and smooth without adversely affecting pilot comfort. The design was limited to a two-ship formation and therefore string stability issues were not considered in the design. A proportional-plusintegral-plus-derivative (PID) controller with state feedback was used in this system (fig 3 and 4). Limited by hardware constraints, the control system outputs are longitudinal-stick and lateral-stick commands. The formation controller inputs are lateral-position errors, vertical-position errors, lateral-velocity errors, vertical-velocity errors, local normal acceleration, and local bank angle. Longitudinal position was controlled by the pilot with the throttle.

The guidance and navigation algorithms use a formation reference-frame aligned with a fixed formation-heading (fig 5). Details of the guidance and navigation can be found in reference 6 .

Four different gain-sets were developed and flight-tested. They are referred to as A-gains, B-gains, C-gains, and D-gains. The A-gains were designed with high stability margins and were used for initial tests of the system in flight. The B-gains were designed to meet performance goals with adequate stability margins. The C-gains were designed with lower stability margins to allow better performance. The D-gains were designed to give zero steady-state error in the presence of sensor biases. The D-gains are the only gains with a nonzero position integral term.

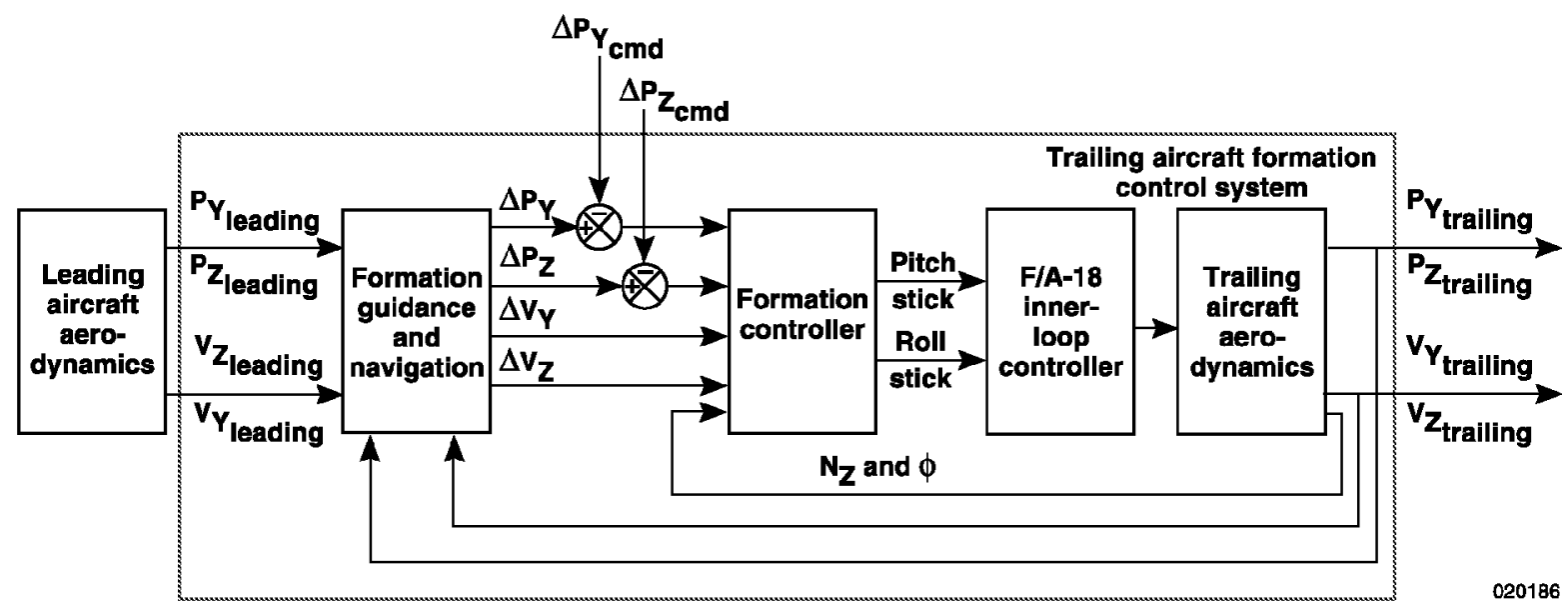

Figure 2. Formation flight control system. 


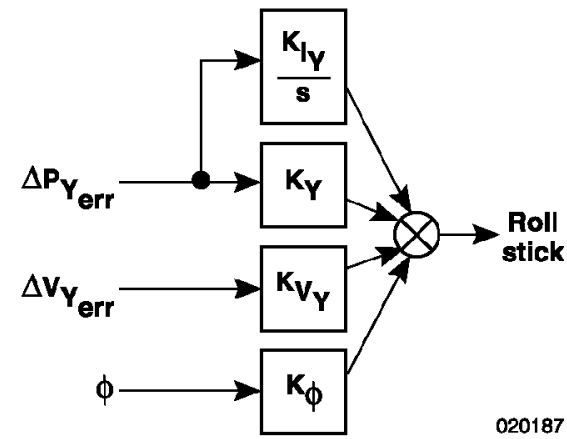

Figure 3. Lateral formation control system.

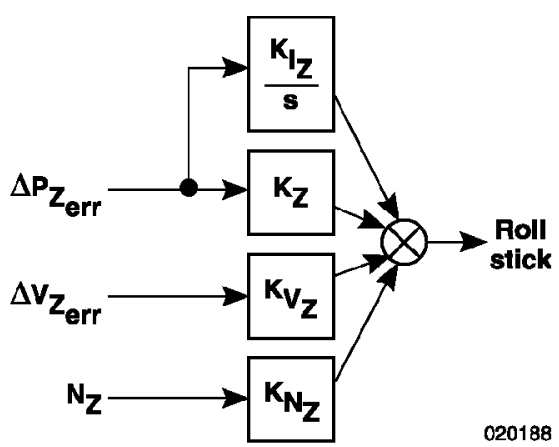

Figure 4. Vertical formation control system.

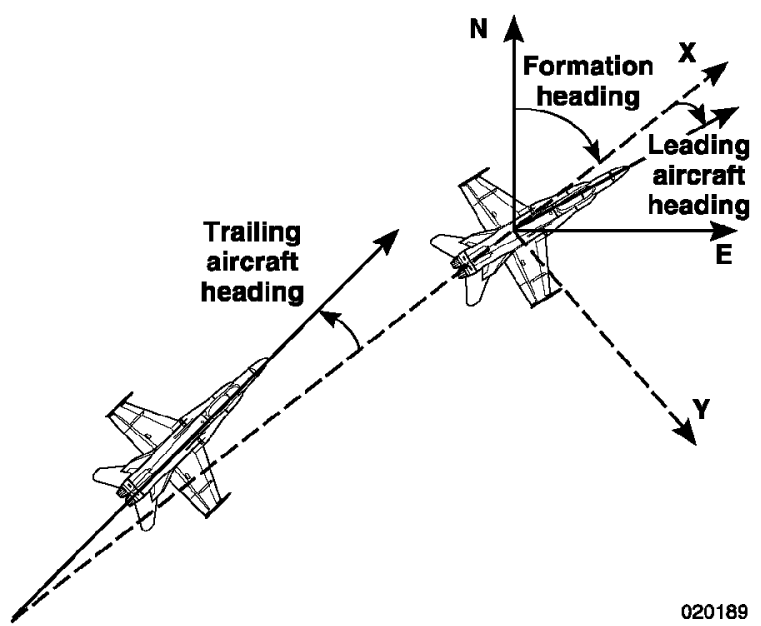

Figure 5. Formation reference frame.

\section{Linear String Stability}

This paper investigates the effects of extending the AFF two-ship formation controller to an $n$-ship formation. It was expected that an $n$-ship formation would be string-unstable; however, the authors were interested in attempting to quantify the degree to which the performance of the system and ride quality degraded with such a control system.

Two types of stability are used in this paper; bounded-input-bounded-output (BIBO) stability and string stability. The BIBO stability of a single linear system (individual stability) is met if the real part of each pole of the system is negative. ${ }^{11}$ A formation of aircraft is BIBO-stable if bounded motion of the $1^{\text {st }}$ aircraft results in bounded motion of the $n^{\text {th }}$ aircraft. String stability only describes the growth or decay of errors in the formation.

The cascaded system shown in figure 6 is used to approximate $n$ aircraft flying under formation control. Each identical system, $G(s)$, attempts to follow the position of the preceding system. Here $G(s)$ is a linear single-input-single-output (SISO) system that is assumed to be individually stable. Sheikholeslam and Desoer $^{12}$ show that a cascaded system of identical vehicles $(\mathrm{G}(\mathrm{s}))$ will be string stable if

$$
|G(j \omega)|<1 \quad \text { for all } \omega>0
$$

where $j \omega$ is substituted for $s$ because $\sigma=0$ for constant oscillatory motion. A cascaded system that satisfies equation (1) will attenuate formation errors. The $n^{t h}$ aircraft of a string stable system will attenuate motion of the $1^{\text {st }}$ aircraft. If the system is string unstable according to equation (1), then errors will be amplified by the formation.

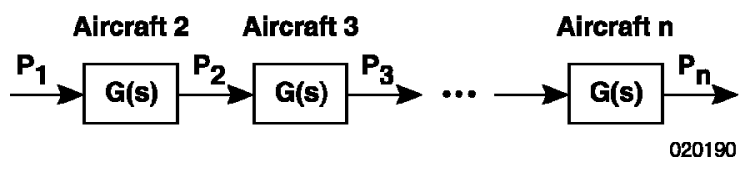

Figure 6. Cascaded formation flight system.

If the formation size is finite and known, then the formation can be BIBO-stable even if the system is string unstable by eq (1). The transfer function of the formation shown in figure 6 with input $P_{1}$ and output $P_{n}$ is

$$
\frac{P_{n}(s)}{P_{1}(s)}=(G(s))^{n-1}
$$


where $n$ is the number of aircraft connected in series formation and $P_{i}$ is the position of the $i^{\text {th }}$ aircraft. The formation transfer function $(G(s))^{n-1}$ has $n-1$ multiple poles and $n-1$ multiple zeros of $\mathrm{G}(\mathrm{s})$. If $\mathrm{G}(\mathrm{s})$ is individually stable then the formation will be BIBO stable.

Consider the two second-order systems:

$$
\begin{gathered}
G_{1}(s)=\frac{100}{s^{2}+6 s+100} \\
G_{2}(s)=\frac{100}{s^{2}+16 s+100}
\end{gathered}
$$

with transfer function magnitudes shown in figure 7. $\mathrm{G}_{1}(\mathrm{~s})$ is string unstable according to equation (1) and a formation of these systems would amplify a $10 \mathrm{rad} / \mathrm{sec}$ sinusoidal input. If the input to $\mathrm{G}_{1}$ (s) were removed and the formation size was finite, all systems in the formation would return to zero because each system is individually stable. For comparison, $\mathrm{G}_{2}(\mathrm{~s})$ is string stable and would not amplify errors when connected in series.

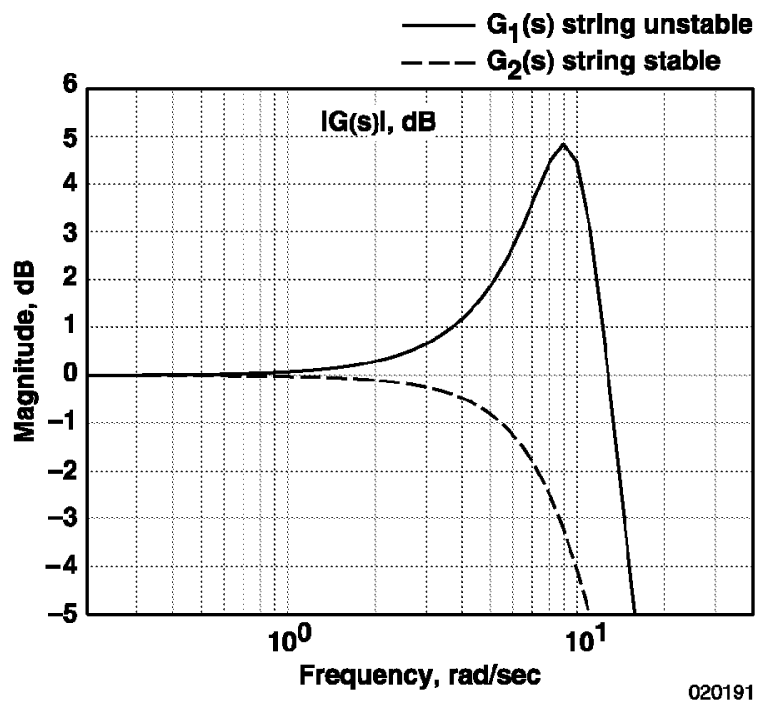

Figure 7. Magnitude of closed-loop transfer functions from second-order example. $\mathrm{G}_{1}$ is string unstable, $\mathrm{G}_{2}$ is string stable.
Figure 8 shows the step responses of the two systems when connected in series. The response of $\mathrm{G}_{1}(\mathrm{~s})$ shows the exponential amplification of errors caused by string instability. Also note that since $\mathrm{G}_{1}(\mathrm{~s})$ and $\mathrm{G}_{2}(\mathrm{~s})$ are both individually stable, errors go to zero when the input is held steady. A string unstable formation of systems such as $\mathrm{G}_{1}(\mathrm{~s})$ will have an unbounded output only if the formation size is infinite.

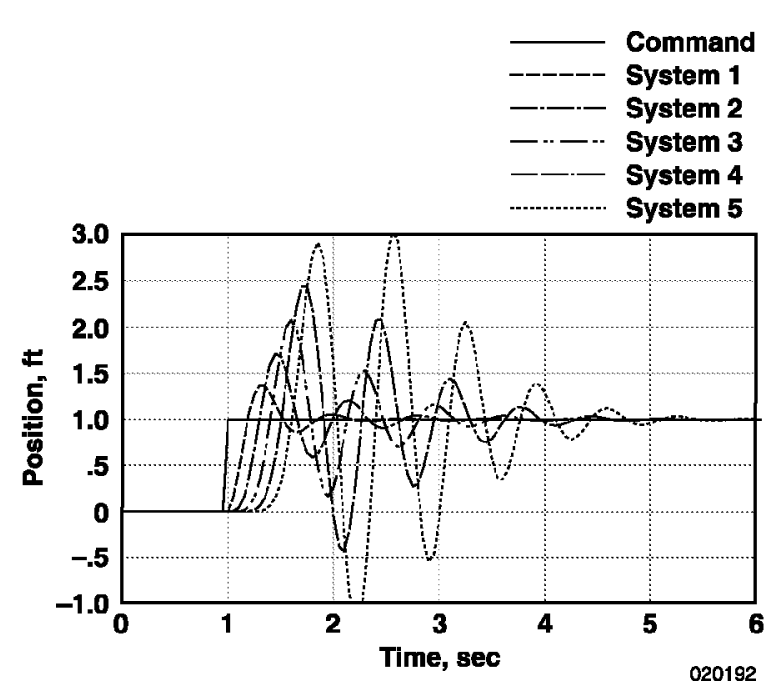

(a) $G_{1}(s)$.

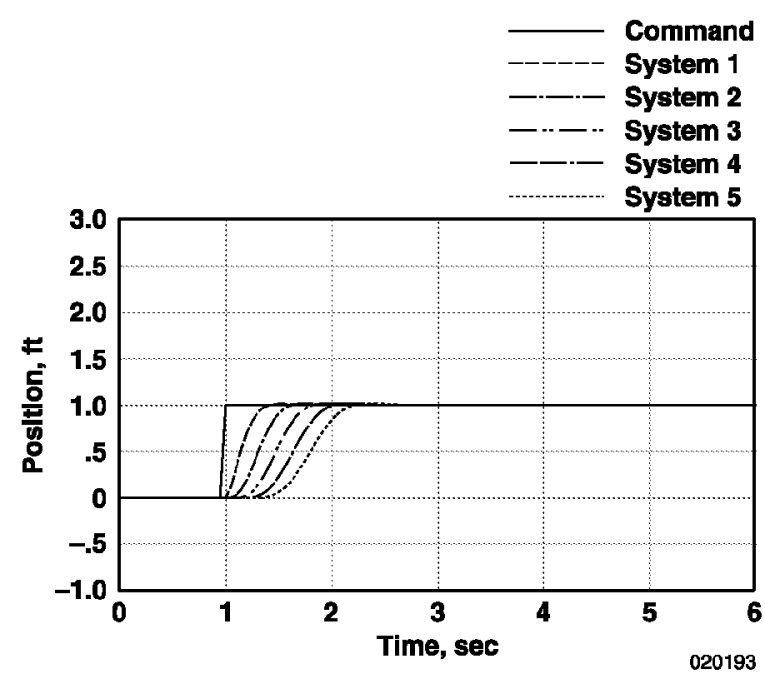

(b) $\mathrm{G}_{2}(\mathrm{~s})$.

Figure 8. Step response of a string unstable system and a string stable system with five aircraft. 
For string stability analysis an absolute-position error was defined as the difference between the aircraft position $\left(\mathrm{P}_{\mathrm{i}}\right)$ and its initial position $\left(\mathrm{P}_{\mathrm{o}, \mathrm{i}}\right)$.

$$
E_{i, a b s}=P_{i}-P_{o, i}
$$

The absolute-position error ( $\left.E_{i, a b s}\right)$ in equation (3) is different than the relative-position error used by the controller.

$$
E_{i, r e l}=P_{i}-P_{i-1}
$$

Each aircraft is assumed to have an initial relative-position error of zero.

In a worst-case scenario, the formation will be excited by constant oscillatory motion. The absolute-position error amplitude ratio of the $n^{\text {th }}$ aircraft to the first aircraft for sinusoidal input is given in equation (5). For this analysis, the excitation is restricted to be only on the $1^{\text {st }}$ aircraft.

$$
|G(j \omega)|^{n-1}=\frac{a m p\left(E_{n, a b s}\right)}{a m p\left(E_{1, a b s}\right)} \quad \text { for any } \omega>0
$$

Equation (5) can be used to predict the largest amplitude of oscillation possible for the $n^{t h}$ aircraft due to motion of the $1^{\text {st }}$ aircraft at a given frequency.

The peak magnitude of $G(j \omega)$, referred to as $M_{m}$, defines the maximum value of equation (5). Substituting the frequency at which $\mathrm{M}_{\mathrm{m}}$ occurs, $\omega \mathrm{m}$, into equation (5) produces equation (6).

$$
\left(M_{m}\right)^{n-1}=\max \left[\frac{\left(E_{n, a b s}\right)}{\left(E_{1, a b s}\right)}\right]=R_{n}
$$

Equation (6) can be used as a bound on the system for string stability during the design of the controller. This gives the designer an initial look at the degree of string instability of the system and a tool for linear control design. Equation (6) does not replace nonlinear formation simulation or ride quality analysis described later in this paper. System excitation at a different frequency, or with non-sinusoidal motion, will result in a response that is less than the response predicted by equation (6). Equation (6) is only valid if the communication parameters between the aircraft are single-input-single-output (SISO).

An important observation from equation (6) is that the amplitude of the absolute-position error is not affected by the phase lag of $\mathrm{G}(\mathrm{s})$ or the time delay of the interaircraft communications. These effects degrade tracking performance but do not determine the peak motion of the $n^{t h}$ aircraft described by equation (6).

\section{Conversion of the AFF System to a}

Single-Input-Single-Output System

The AFF system (fig 2) was converted to a linear SISO model so that equation (6) could be used. The system was not broken into separate lateral and vertical SISO models because of the possibility that a combination of lateral and vertical inputs could be the worst-case input. First, it was assumed that the system input only consists of leading aircraft motion. All other inputs and disturbances were assumed to be zero. The second assumption was that the leading aircraft velocities could be exactly calculated from the leading aircraft positions. With these assumptions, the system was reduced to a two-input two-output system. The two inputs were leading aircraft $Y$ position, $P_{Y_{\text {leading }}}$, and leading aircraft $Z$ position, $P_{Z_{\text {leading }}}$. The two outputs were trailing aircraft $Y$ position, $P_{Y_{\text {trailing }}}$ and trailing aircraft $Z$ position, $P_{Z_{\text {trailing }}}$.

An independent variable $\left(\gamma_{1}\right)$ was created for the purpose of combining the lateral and vertical axes of the system in order that a worst-case combination of inputs could be used. The two inputs were parameterized with input direction $\gamma_{1}$ using equation (7) and equation (8).

$$
\begin{gathered}
P_{Y_{\text {leading }}}=P_{\text {in }} \cdot \cos \left(\gamma_{1}\right) \\
P_{Z_{\text {leading }}}=P_{\text {in }} \cdot \sin \left(\gamma_{1}\right)
\end{gathered}
$$

The further assumption of a constant $\gamma_{1}$ reduces the system input to one parameter, $P_{i n}$. The two system outputs were combined in a similar fashion by defining $\gamma_{2}$ and $P_{\text {out }}$

$$
\begin{gathered}
\gamma_{2}=\tan ^{-1}\left(\frac{P_{Z_{\text {trailing }}}}{P_{Y_{\text {trailing }}}}\right) \\
P_{\text {out }}=\left(\sqrt{P_{Y_{\text {trailing }}^{2}}^{2}+P_{Z_{\text {trailing }}}^{2}}\right) \\
\cdot \cos \left(\gamma_{2}-\gamma_{1}\right)
\end{gathered}
$$


Equations (7) and (8) force the leading aircraft to move along a line defined by the fixed angle $\gamma_{1}$ and equations (9) and (10) project the two trailing aircraft positions onto the same line to form a single trailing aircraft position, $P_{\text {out }}$. Figure 9 shows pictorially how $\gamma_{1}$ was used to create $P_{\text {in }}$ and $P_{\text {out }}$. The resulting SISO system is shown in figure 10 .

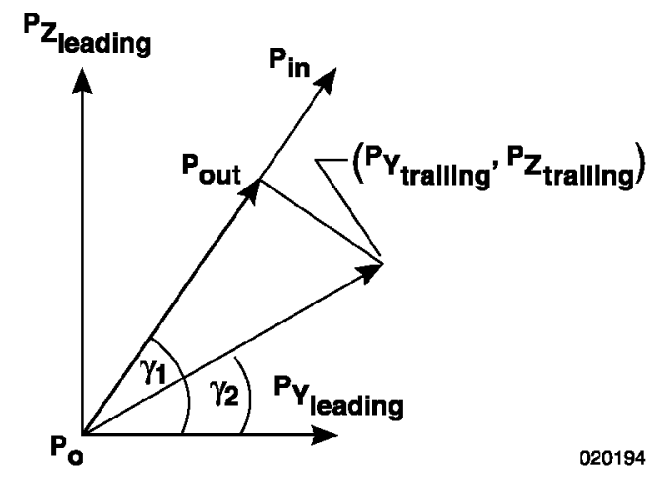

Figure 9. Parameterization of lateral and vertical positions into $\mathrm{P}_{\text {in }}$ and $\mathrm{P}_{\text {out }}$.

\section{Linear Results}

The string stability analysis was performed at the input direction $\left(\gamma_{1}\right)$ that yielded the highest peak of the closed-loop transfer function $\left(M_{m}\right)$ for each gain-set. The effect of input direction was found by plotting $M_{m}$ with varying values of $\gamma_{1}$ as shown in figure 11 . The input direction that yielded the highest values of $M_{m}$ was found to be $\gamma_{1}=90 \mathrm{deg}$ for all gain-sets. This input direction was used in the linear string stability analysis. Longitudinal string stability was ignored during the linear analysis because longitudinal position was controlled by the pilot.
Figure 12 shows the magnitude of the closed-loop transfer function of a single formation control system with each of the four gain-sets. Linear models of the system were used for this analysis. Each gain-set results in a system with a peak that is greater than $1.0(0 \mathrm{~dB})$ and is therefore string unstable according to equation (6). The data in figure 12 show a trend of higher peak magnitudes for higher bandwidths, indicating a tradeoff between performance and string stability for this system in agreement with previous work. $^{13}$

\section{Nonlinear Formation Performance}

Formation performance is based on the relative-position error described by equation (4). String instability can cause the relative-position tracking performance of the $n^{\text {th }}$ aircraft to degrade beyond acceptable limits. Formation performance can be analyzed with linear system models connected in series or with nonlinear formation simulation. A 6-DOF nonlinear formation flight simulation was used in this analysis. ${ }^{14}$ Formations were simulated by performing multiple runs of a single aircraft and formation autopilot simulation. ${ }^{10}$ The $i^{\text {th }}$ aircraft tracked the motion of a previously recorded $(i-1)^{\text {th }}$ aircraft simulation. This process was repeated for each aircraft in formation. The combinations of lateral and vertical inputs to the formation were determined using equations (7) and (8).

Two test cases were chosen for nonlinear formation performance analysis to represent the set of all inputs expected to occur during flight. The first test case was a step input on the relative-position command of the first aircraft in formation. The second test case used only light turbulence to excite the formation.

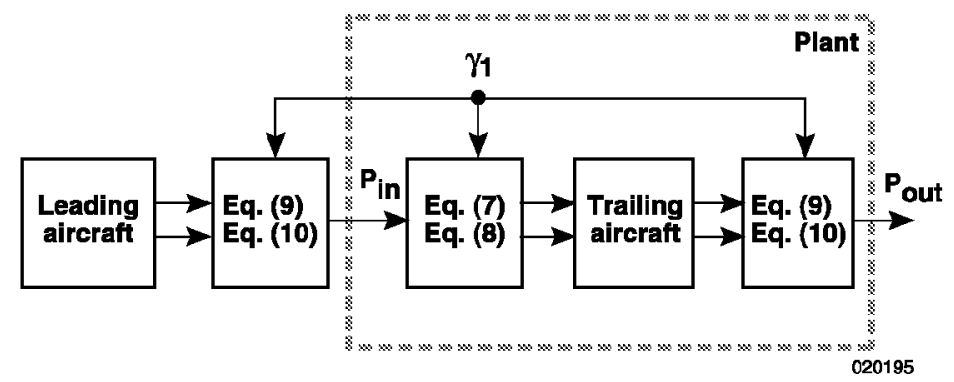

Figure 10. Single-input-single-output representation of the formation control system. 


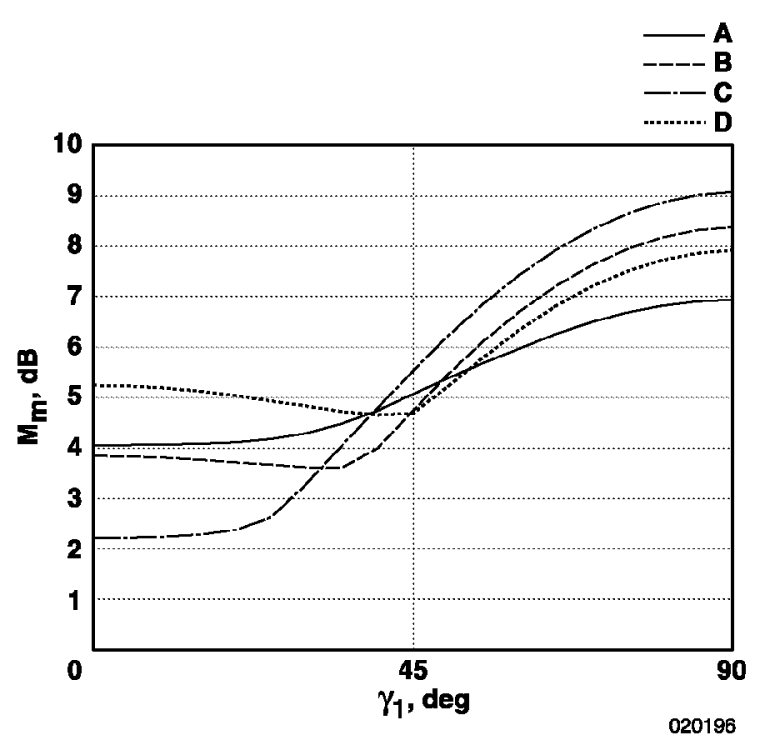

Figure 11. Input direction survey.

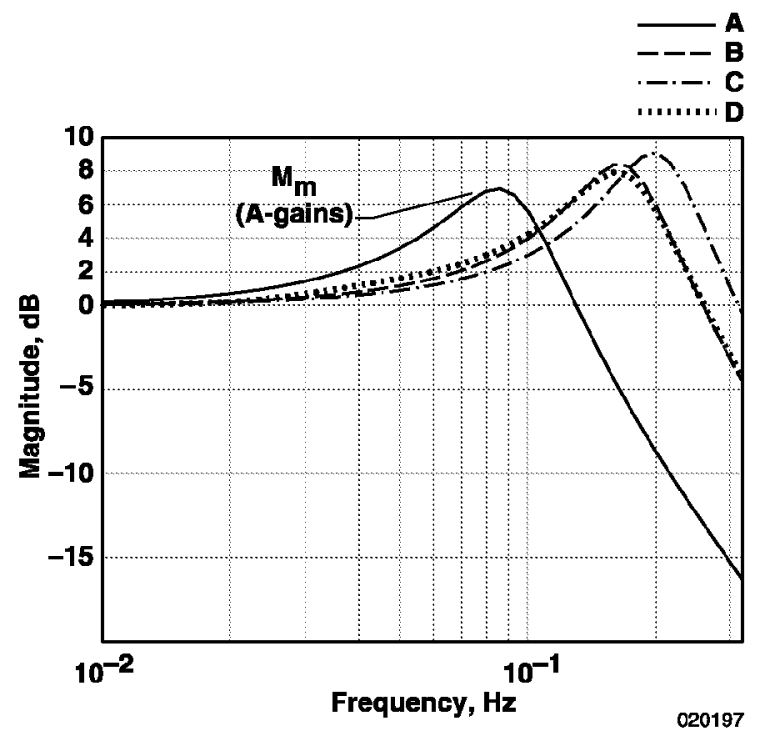

Figure 12. Magnitude of closed-loop transfer functions for gain-sets A, B, C, and D.

\section{Nonlinear Formation Performance Results}

The absolute positions of each aircraft in a seven-aircraft formation, due to step excitation, are plotted in figure 13. The A-gains were used for this test. Step commands on the relative-position command of $\pm 10 \mathrm{ft}$ were given to the 1st aircraft to excite the formation. The nonzero initial conditions of some of the aircraft are a result of error magnification that occurred before the maneuver began. The exponential magnification of errors in this formation is a result of string instability. Formations using the B-, C-, and D-gains were also simulated. Results of these simulations show that the B-, C-, and D- gains all have higher step responses than the A-gains.

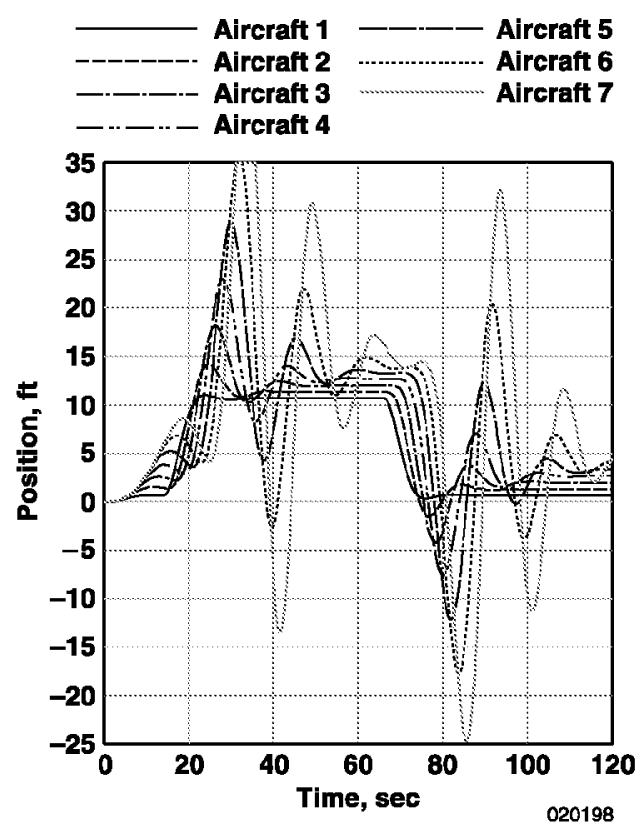

Figure 13. Six degrees-of-freedom nonlinear formation simulation using A-gains with step command excitation at the first aircraft.

The results from the nonlinear formation simulation with step input excitation were compared to the linear results from equation (6). The absolute error ratio of the $3^{\text {rd }}$ aircraft to the $1^{\text {st }}$ aircraft for each gain-set is plotted in figure 14. These comparisons show that the linear analysis technique is very conservative for predicting the response of the formation to step inputs. This result is expected because equation (6) used the assumption of constant sinusoidal input at a frequency chosen to give the highest absolute-position errors. Step inputs give a good indication of the system dynamics, but do not excite string stability dynamics as well as constant oscillatory input.

The simulation of a seven-aircraft formation in light turbulence using A-gains yielded less severe aircraft motion. Relative-position commands were set to zero for these tests. Figure 15 shows the positions of a seven-aircraft formation in light turbulence using the 


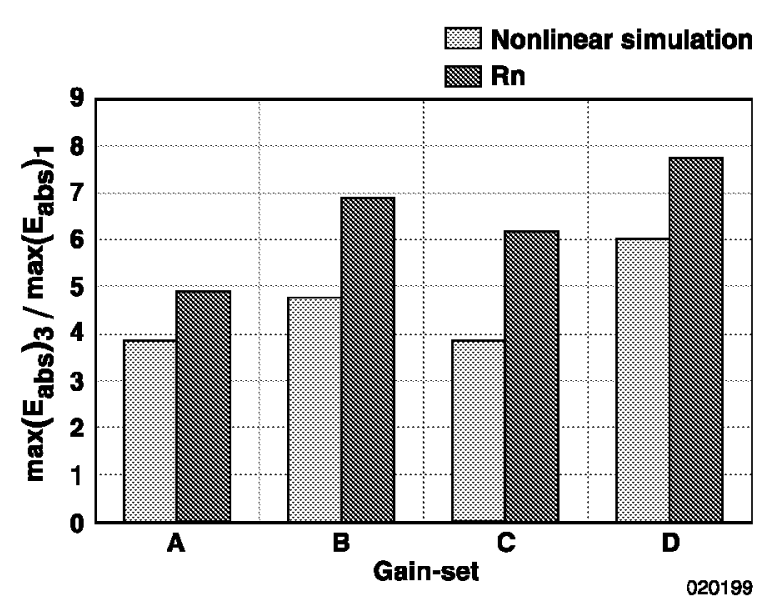

Figure 14. Comparison of nonlinear and linear string stability results for the third aircraft

A-gains. The motion of the first three aircraft is dominated by gust response, but the remaining aircraft in formation seem to be driven more by string instability. The seventh aircraft has constant oscillatory motion with a peak of approximately $20 \mathrm{ft}$ and a frequency of approximately $0.063 \mathrm{~Hz}$. Note that $\omega_{m}$ for the A-gains is $0.086 \mathrm{~Hz}$. Although excited by random gusts, the aircraft near the back of the formation became oscillatory with a frequency of oscillation close to $\omega_{m}$.

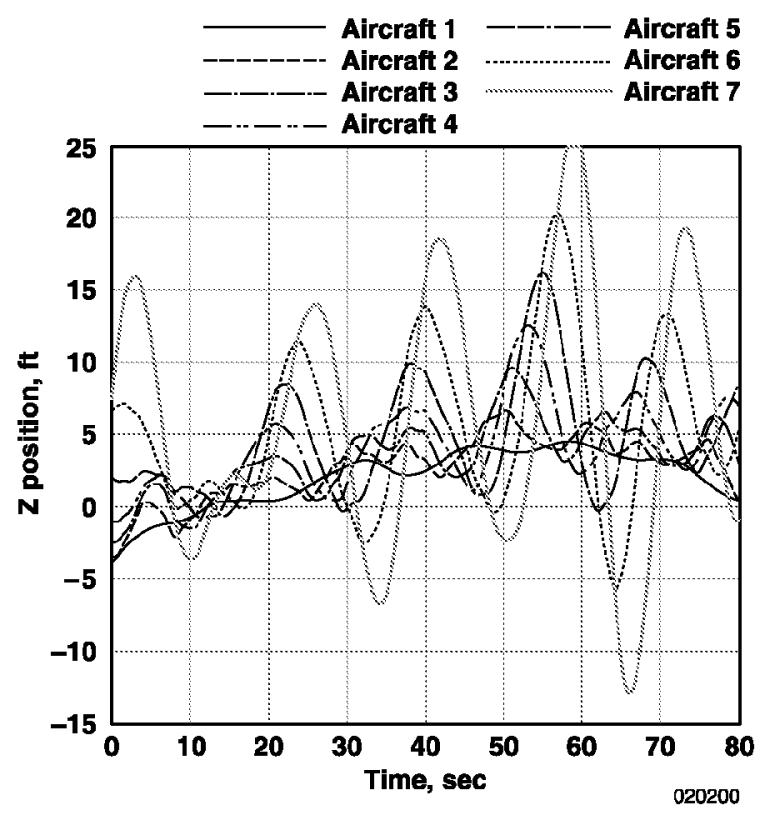

Figure 15. Aircraft position from 6-DOF nonlinear formation simulation with light turbulence using A-gains.
Each aircraft in the seven-aircraft formation using the A-gains meets the AFF phase-0 goal of a standard deviation of relative-position error that is less than $9 \mathrm{ft}$ in light gusts. ${ }^{6}$ The AFF goal was intended for use with two-aircraft formations, but is used here as a semiarbitrary limit of relative-position tracking performance. Figure 16 shows the relative-position error of each aircraft in formation in light gusts. Comparison of figure 15 to figure 16 illustrates the difference between absolute aircraft motion predicted by equation (6) and relative tracking performance given by equation (4). The absolute-position errors are larger and grow quicker than the relative-position errors. This is because the relative-position errors are reduced when the aircraft are in phase with each other.

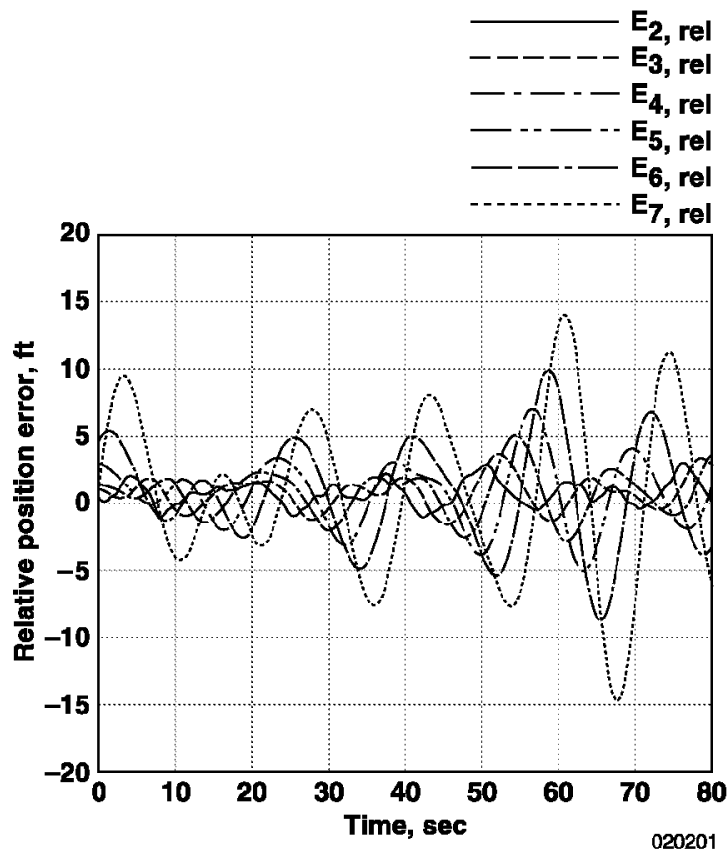

Figure 16. Aircraft relative position from 6-DOF nonlinear formation simulation with light turbulence using A-gains.

The standard deviation of relative-position error for each of the four gain-sets is plotted in figure 17. This figure compares the relative-position tracking performance of each aircraft to the $9 \mathrm{ft}$ standard deviation limit used for this study. The C-gains are limited by performance at the 5 th aircraft. The A-gains have sufficient tracking performance with up to seven aircraft in formation. The design of the A-gains with increased stability margins resulted in a gain-set with low bandwidth but improved string stability characteristics when compared to other gain-sets. 


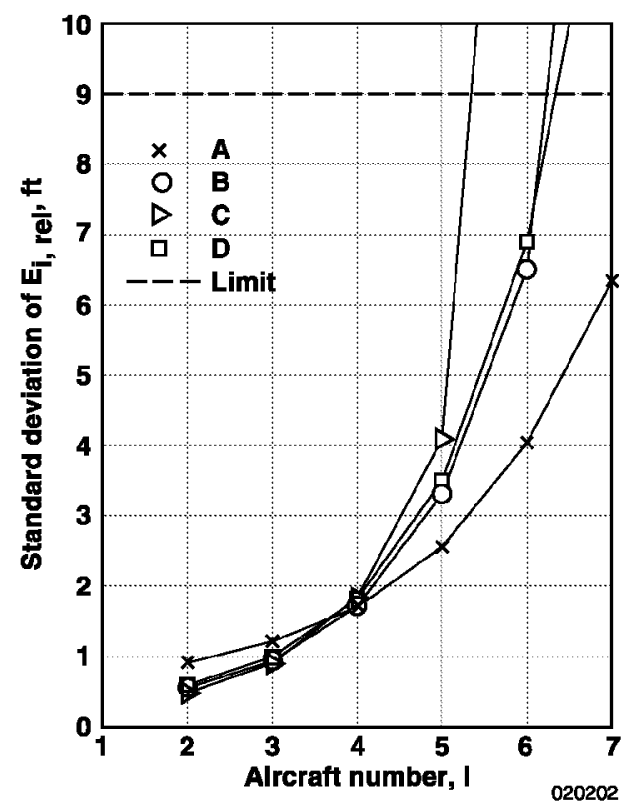

Figure 17. Relative-position error standard deviations for each gain-set.

\section{$\underline{\text { Ride Quality Analysis }}$}

String instability also adversely affects aircraft ride quality. "Ride quality" typically describes the passenger's level of comfort. Measurements made using the nonlinear formation simulations were used to assess the ride quality at the $i^{\text {th }}$ aircraft. The International Organization for Standardization (ISO) standard for motion sickness ${ }^{15}$ was used to translate the accelerations experienced into a measure of pilot comfort. More specifically, motion sickness dose values (MSDV) were calculated for each of the $n$ aircraft in the formation. The MSDV has been defined such that higher values correspond to greater likelihood of motion sickness. The MSDV for vertical acceleration is defined as

$$
M S D V_{z}=\left\{\int_{0}^{T}\left[a_{w}(t)\right]^{2} d t\right\}^{1 / 2}
$$

here $a_{w}$ is a frequency-weighted acceleration in the $\mathrm{z}$-direction and $\mathrm{T}$ is the total period during which motion could occur. Data used in the ride-quality analysis was taken from time histories from the nonlinear formation simulation lasting 200 seconds. Lateral ride-quality analysis was not performed because lateral acceleration weightings are not given in the ISO standard for motion sickness and because lateral accelerations were found to be significantly lower than vertical accelerations during these tests.
The limit for acceptable ride quality was found by limiting the percentage of the general population that would vomit after an hour of flight in these conditions. A limit of 10 percent was chosen because it has been used in previous ride-quality analysis with military aircraft. ${ }^{16} \mathrm{~A} K_{m}$ factor of one-third was used in this analysis. ${ }^{15}$ Ride-quality limits and $K_{m}$ factors will vary with aircraft type, mission, and passenger characteristics.

\section{Ride Quality Results}

Figure 18 shows the ride quality of each aircraft in formation for each gain-set. An unexpected result of this analysis is that gain-sets B, C, and D are all constrained more by ride quality than by relative-position tracking performance. This is because the aircraft motion resulting from string instability determined by the $M_{m}$ values of the B-, C-and D-gains occur at a frequency that is conducive to motion sickness. This can be seen by comparing the magnitude plots of the closed-loop transfer functions to the frequency-weighting curve given in ISO-2631-1 for motion sickness (figure 19). The A-gains have reduced $\mathrm{MSDV}_{\mathrm{z}}$ values because they have better string stability and because the ISO frequency-weighting curve at the value of $\omega_{m}$ for the $\mathrm{A}$-gains is not weighted as heavily.

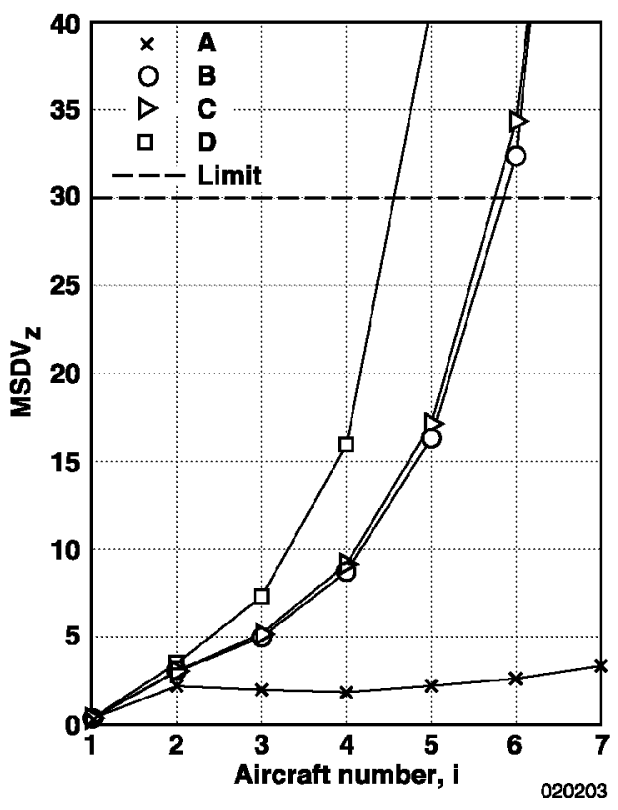

Figure 18. Aircraft ride quality from nonlinear formation simulation data with light gusts. High MDSV indicate poor ride quality. 


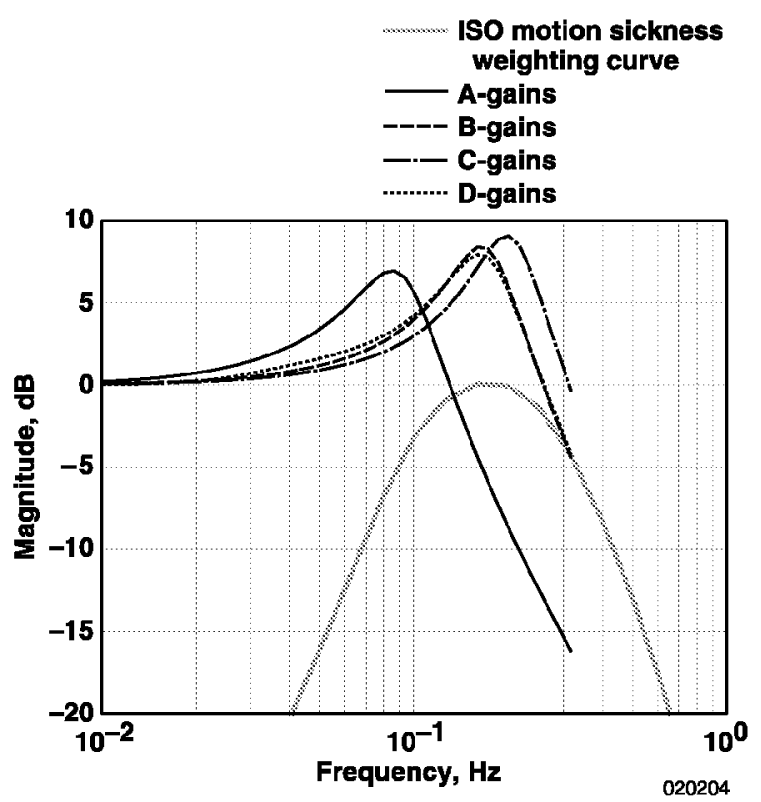

Figure 19. Comparison of linear closed-loop transfer function magnitudes to the ISO-2631 motion sickness frequency weighting curve.

\section{$\underline{\text { Concluding Remarks }}$}

Analysis techniques in this paper can be used to determine the effect of string instability on an aircraft under autonomous formation control. Linear analysis, nonlinear performance analysis, and ride-quality analysis were used to analyze a formation flight system for string stability. The three analysis methods were applied to a formation control system using F/A-18 aircraft to demonstrate the results of string instability.

The linear string stability equations provided in this paper can be used to determine a relative measure of string stability. The equations show that the amplitude of oscillation of the aircraft in a cascaded formation is not affected by the phase lag of each closed-loop formation system or by the interaircraft communication delay. The linear technique discussed in this paper could be applied to the design of a formation control system to conservatively limit a SISO system for string stability.

Performance analysis was executed with a nonlinear simulation of the system. Nonlinear formation simulation also demonstrated the conservativeness of the linear analysis. Formation simulation performed with excitation consisting of only light turbulence produced oscillatory motion of the aircraft in the back of the formation. The frequency of oscillation was nearly equal to the frequency of the peak magnitude of the closed-loop transfer function of the system. Adequate performance with formations of up to seven aircraft could be obtained using the A-gains in light turbulence.

The ride quality of each aircraft in formation was evaluated for four gain-sets using the nonlinear simulation and the ISO-2631 standard. ${ }^{15}$ Three of the gain-sets are limited more by ride quality than by performance. The exception is the A-gains, because the magnifications of position errors caused by string instability occur at a lower frequency. Each aircraft in a seven-aircraft formation using A-gains would meet performance specifications and have adequate ride quality.

A string unstable formation control system can be considered when the formation size is limited and the guidance and communication are similar to the system presented in this paper. It is recommended that a string stability constraint is included in the design of such systems.

\section{$\underline{\text { References }}$}

${ }^{1}$ Liang, Chi-Ying and Huei Peng, "Optimal Adaptive Cruise Control with Guaranteed String Stability," Vehicle System Dynamics, Vol. 31 (1999), pp. 313-330.

${ }^{2}$ Gehring, Ottmar and Hans Fritz, "Practical Results of a Longitudinal Control Concept for Truck Platooning with Vehicle to Vehicle Communication," IEEE Conference on Intelligent Transportation Systems, ITSC '97, November 1997, Boston, MA

${ }^{3}$ Wang, Yibing and Zengjin Han, "Stability of an Automated Vehicle Platoon," Proceedings of the American Control Conference, Philadelphia, Pennsylvania, June 1998.

${ }^{4}$ Kaminer, Isaac, Antonio Pascoal, Eric Hallberg, and Carlos Silvestre, "Trajectory Tracking for Autonomous Vehicles: An Integrated Approach to Guidance and Control," Journal of Guidance, Control, and Dynamics, Vol. 21, No. 1, Jan-Feb 1998.

${ }^{5}$ Swaroop, D., J.K. Hedrick, C. C. Chien, and P. Ioannou, "A Comparison of Spacing and Headway Control Laws for Automatically Controlled Vehicles," Vehicle System Dynamics, Vol. 23 (1994), pp. 597-625.

${ }^{6}$ Hanson, Curtis E., Jack Ryan, Michael J. Allen, and Steven R. Jacobson, "An Overview of Flight Test Results for a Formation Flight Autopilot", American Institute of Aeronautics and Astronautics, Guidance, 
Navigation, and Control Conference, Monterey, California, August 2002. (publishing concurrently)

${ }^{7}$ Beukenberg, Markus and Dietrich Hummel, "Aerodynamics, Performance and Control of Airplanes in Formation Flight," Proceedings of the International Council of the Aeronautical Sciences, Stockholm, Sweden, Sept. 9-14, 1990.

${ }^{8}$ Hummel, Dietrich, "Formation Flight as an Energy-Saving Mechanism", Israel Journal of Zoology, Vol. 41, March, 1995. pp. 261-278.

${ }^{9}$ Weimerskirch, Henri, Julien Martin, Yannick Clerquin, Peggy Alexandre, and Sarka Jiraskova "Energy Saving in Flight Formation," Nature, Vol. 413, 18 Oct. 2001, pp. 697 and 698.

${ }^{10}$ Ryan, Jack, Curtis E. Hanson, Ken A Norlin, and Michael J. Allen, "Data Synchronization Discrepancies in a Formation Flight Control System," Proceedings of SFTE 32nd Annual International Symposium, 10-14 Sept. 2001, Seattle, Washington.

${ }^{11}$ Chen, Chi-Tsong, Linear System Theory and Design, Oxford University Press, New York, 1999.

${ }^{12}$ Sheikholeslam, Shahab and Charles A. Desoer, "Longitudinal Control of a Platoon of Vehicles with no Communication of Lead Vehicle Information: A System Level Study," IEEE Transactions on Vehicular Technology, Vol. 42, No. 4 Nov. 1993.

${ }^{13}$ Swaroop, D. and J. K. Hedrick, "String Stability of Interconnected Systems," IEEE Transactions on Automatic Control, Vol. 41, No. 3, March 1996.

${ }^{14}$ Norlin, Ken A. Flight Simulation Software at NASA Dryden Flight Research Center. NASA TM 104315, Oct. 1995.

${ }^{15}$ International Organization for Standardization, Mechanical Vibration and Shock - Evaluation of Human Exposure to Whole-Body Vibration. Part 1, General Requirements, ISO 2631-1:1997(E).

${ }^{16}$ Jacobson, S. and Moynes, J. "Ride Qualities Criteria for the B-2 Bomber," AIAA 90-3256, AIAA/AHS/ASEE Aircraft Design, Systems and Operations Conference, Sept 17-19, 1990. 
Public reporting burden for this collection of information is estimated to average 1 hour per response, including the time for reviewing instructions, searching existing data sources, gathering and maintaining the data needed, and completing and reviewing the collection of information. Send comments regarding this burden estimate or any other aspect of this collection of information, including suggestions for reducing this burden, to Washington Headquarters Services, Directorate for Information Operations and Reports, 1215 Jefferson Davis Highway, Suite 1204, Arlington, VA 22202-4302, and to the Office of Management and Budget, Paperwork Reduction Project (0704-0188), Washington, DC 20503.

\begin{tabular}{|l|l|l|}
\hline 1. AGENCY USE ONLY (Leave blank) & $\begin{array}{l}\text { 2. REPORT DATE } \\
\text { August } 2002\end{array}$ & $\begin{array}{l}\text { 3. REPORT TYPE AND DATES COVERED } \\
\text { Technical Memorandum }\end{array}$ \\
\hline
\end{tabular}

4. TITLE AND SUBTITLE

String Stability of a Linear Formation Flight Control System

6. AUTHOR(S)

Michael J. Allen, Jack Ryan, James F. Parle, and Curtis E. Hanson

NASA Dryden Flight Research Center

P.O. Box 273

Edwards, California 93523-0273

National Aeronautics and Space Administration

Washington, DC 20546-0001

\section{FUNDING NUMBERS}

WU 706-35-00-E8-20-00-AFF
8. PERFORMING ORGANIZATION

REPORT NUMBER

H-2504

\section{SUPPLEMENTARY NOTES}

Also presented at the AIAA Guidance, Navigation, and Control Conference, Monterey, California, August 5-8, 2002.

\begin{tabular}{l|l}
\hline 12a. DISTRIBUTION/AVAILABILITY STATEMENT & 12b. DISTRIBUTION CODE \\
Unclassified-Unlimited & \\
Subject Category - 08 & \\
This report is available at http://www.dfrc.nasa.gov/DTRS/ &
\end{tabular}

13. ABSTRACT (Maximum 200 words)

String stability analysis of an autonomous formation flight system was performed using linear and nonlinear simulations. String stability is a measure of how position errors propagate from one vehicle to another in a cascaded system. In the formation flight system considered here, each $i$ th aircraft uses information from itself and the preceding $\left((i-1)^{t h}\right)$ aircraft to track a commanded relative position. A possible solution for meeting performance requirements with such a system is to allow string instability. This paper explores two results of string instability and outlines analysis techniques for string unstable systems. The three analysis techniques presented here are: linear, nonlinear formation performance, and ride quality. The linear technique was developed from a worst-case scenario and could be applied to the design of a string unstable controller. The nonlinear formation performance and ride quality analysis techniques both use nonlinear formation simulation. Three of the four formation-controller gain-sets analyzed in this paper were limited more by ride quality than by performance. Formations of up to seven aircraft in a cascaded formation could be used in the presence of light gusts with this string unstable system.

\begin{tabular}{|c|c|c|c|}
\hline \multirow{2}{*}{\multicolumn{3}{|c|}{$\begin{array}{l}\text { 14. SUBJECT TERMS } \\
\text { Aircraft, Formation, Leader-follower, Stability, String }\end{array}$}} & \multirow{2}{*}{$\begin{array}{l}\text { 15. NUMBER OF PAGES } \\
16 \\
\text { 16. PRICE CODE }\end{array}$} \\
\hline & & & \\
\hline $\begin{array}{l}\text { 17. SECURITY CLASSIFICATION } \\
\text { OF REPORT } \\
\text { Unclassified }\end{array}$ & $\begin{array}{l}\text { 18. SECURITY CLASSIFICATION } \\
\text { OF THIS PAGE } \\
\text { Unclassified }\end{array}$ & $\begin{array}{l}\text { 19. SECURITY CLASSIFICATION } \\
\text { OF ABSTRACT } \\
\text { Unclassified }\end{array}$ & $\begin{array}{l}\text { 20. LIMITATION OF ABSTRACT } \\
\text { Unlimited }\end{array}$ \\
\hline
\end{tabular}

